\title{
The Ecuadorian Physiotherapist in National Printed Media: A Pilot Study of the Image of a Health Practitioner
}

\author{
Sergiy Voznesenskyy $1^{*}$ \\ Tetyana Zaviryukha² \\ Pedro Pablo Figueroa-Andrade ${ }^{1}$ \\ Sofia Maribel Moya-Collantes ${ }^{1}$ \\ ${ }_{1}$ Pontifical Catholic University of Ecuador, Quito, Ecuador \\ ${ }^{2}$ W. A. Mozart Conservatory of Music and Arts, Quito, Ecuador \\ *Corresponding author. E-mail: svoznesenskyy002@puce.edu.ec
}

Doi:10.5901/mjss.2015.v6n6s4p538

\begin{abstract}
Corpus linguistics provides tools used to answer society and health related questions. In this pilot study, the feasibility of a corpus-driven analysis to reveal themes associated with the image of the Ecuadorian physiotherapy practitioner in the national printed media was investigated. A specialised corpus of newspaper articles was created by selecting relevant articles published in two Ecuadorian national newspapers in 2010-2015. Frequencies, concordances, and collocations of the term 'fisioterapista' were analysed, and a content analysis on the titles of the articles, sections in which they appeared and the tags which were assigned to their online publications was performed. Noun and adjective collocates of the node term 'fisioterapista' in the corpus were assigned to relevant WordNet semantic domains, with the domains of sport and medicine comprising the majority of the collocations. The physiotherapy profession in the media appeared to be male-dominated, despite the factual evidence from the field to the contrary. The results of this study indicate that the corpus-driven analysis is feasible to sketch the image of the Ecuadorian physiotherapist in national printed media. In general, the articles studied presented to the public the image of the physiotherapy professional in a stereotypical and distorted manner. A full-scope research including other national, regional, and local printed media is justified. This article is based on a poster presentation at the $5^{\text {th }}$ International Conference on Humanities and Social Sciences held in Roma, Italy on September 25-26 , 2015.
\end{abstract}

Keywords: physiotherapists, Ecuador, public image, printed media, corpus linguistics, content analysis

\section{Introduction}

Corpus linguistics provides an applied methodology that can be useful in revealing pertinent contextual elements and common categories of representation in discourse analysis (Baker et al., 2011; Gabrielatos, McEnery, Diggle \& Baker, 2012). As of recent, this methodology has been massively taught to researchers in both social sciences and humanities (Barrs, 2015). Approaches based on combining corpus linguistics and discourse analysis have been applied to study media representations of different social groups (Baker, Gabrielatos, \& McEnery, 2013; Baker \& Levon, 2015), including members of the medical profession in a specific social context (Baker, P. \& McEnery, 2014).

Examples of some recent pieces of health care research using corpus linguistics tools include exploration of the senses of the term 'stress' in a corpus of non-academic texts, which were thought to influence patient-physician communication (Stvan, 2013), research of the coverage of acquired brain injury in Spanish printed media (Enguix Oliver \& Gallardo Paúls, 2014), and studying adolescent health communication by examining messages posted to an online health forum (Crawford, Brown, Baker, Tischler, \& Abrams, 2015, pp. 74-80). Studying the form and content of language can help health care researchers as well as practitioners to better "understand health" (Crawford et al., 2015, p. 74).

The messages in the media portraying health professionals generate planned and unplanned content that may affect health-related views and behaviours, and in certain cases determine the entire society's perception framework of the profession. The latter is often presented in a very poor and stereotypical manner (Summers \& Summers, 2015, pp. 37-39; Rezaei-Adaryani, Salsali, \& Mohammadi, 2012). In view of the fact that the image of health care practitioners in the media of communication has hardly been studied in the Latin American context, and, in general, no studies using corpus linguistics methodology of the image of physiotherapy practitioners could be found, our research aimed to assess 
the feasibility of a corpus-driven analysis to reveal themes associated with the image of the Ecuadorian physiotherapy practitioner in the national printed media using a small specialised corpus of online versions of newspaper articles.

\section{Methodology}

\subsection{Data}

The newspaper articles analysed in our study were retrieved from the web-sites of two Ecuadorian national printed media, El Comercio (http://www.elcomercio.com/) and El Telégrafo (http://www.telegrafo.com.ec/), the former being the most important newspaper in Quito, the capital of Ecuador, and the Sierra region, and the latter the only public (stateowned) national newspaper in the country (Corporación Humanas Ecuador, 2011). The search term fisioterapista* (which was not case sensitive and with the asterisk (*) serving as a 'wildcard' for any set of zero or more characters) was used for queries to the newspaper websites' internal search engines. Articles published between the $1^{\text {st }}$ of January of 2010 and the $31^{\text {st }}$ of May of 2015 were eligible for inclusion in analysis. Full texts of all articles analysed in this study were freely available online on the publishers' web-sites.

Although the query using only one search term would not retrieve all articles published in the two newspapers that refer to Ecuadorian physiotherapists, the described search strategy could be considered suitable for the purpose of a feasibility study. The word fisioterapista, even though definitely not the only possible noun denoting a practitioner of the profession, is probably the most characteristic and univocal one in the Ecuadorian context, effectively ruling out texts related to foreign practitioners.

After elimination of duplicated texts, our study analysed a specialised corpus of 120 newspaper articles, 74 (62\%) published in El Comercio and 46 (38\%) in El Telégrafo, altogether consisting of 68,654 word tokens and 9,599 word types.

\subsection{Methods}

The methodology of this study was based on the corpus-driven approach, according to which the analysis was guided by the patterns found in the data rather than trying to test a pre-established hypothesis (Baker et al., 2013). As the first stage, the analysis of frequencies of occurrence, concordances, and collocations of the node term fisioterapista* was carried out with the use of the corpus linguistic software AntConc (Anthony, 2013). A new feature added to the build 3.5.0 (Dev) of the software permitted combining the statistical measures of mutual information (MI) and log likelihood (LL) in the Collocates Tool preferences.

In the analysis of the collocates of the noun fisioterapista in the corpus of the newspaper articles we used the following parameters: a combination of the statistics of MI with the threshold of 3 and LL higher than its critical value of 3.84 , corresponding to $p<0.05$; the span of 5 words to the left and right of the query word; no minimum collocate frequency set, and the minimum collocation frequency of 3 . For the purposes of analysis, all function words and personal names were removed from the list of collocates. In terms of the collocation parameter notation proposed by Brezina, McEnery, and Wattam (2015), these settings might be written as '3a+6a-MI(3)+LL( $p<0.05)$, L5-R5, C1-NC3; function words and personal names removed'. The collocates were then categorised according to the most relevant WordNet domains (Bentivogli, Forner, Magnini, \& Pianta, 2004), with the Spanish WordNet accessed through the multilingual lexical online database MultiWordNet 1.4.2 (Cendejas, Barceló, Sidorov, Gelbukh, \& Chanona-Hernandez, 2012).

In order to assess the grammatical gender of the noun fisioterapista in Ecuadorian newspaper articles, we analysed concordances of the node term fisioterapista*, registering the numbers and percent proportions of the articles in which this noun was used in masculine, feminine, or both genders. The grammatical gender was termed 'undetermined' if it could not be unequivocally identified by its formal attributes or the context.

In addition to the analysis of collocates and concordances of the node term fisioterapista ${ }^{*}$, we performed a content analysis on the titles of the articles, sections in which they appeared and the tags assigned to their online publications. 95\% Agresti-Coull confidence intervals were calculated for all percent proportions using the 'binGroup' package (Bilder, Zhang, Schaarschmidt, \& Tebbs, 2010) in the statistical computing environment R (R Core Team, 2015).

\section{Results and Discussion}

The analysis of the collocates of the node term fisioterapista* in the studied newspaper articles discovered 25 most frequent noun and adjective collocates with observed absolute frequency of occurrence in the corpus greater or equal to 
3 (Table 1). Although the node term in our analysis was a noun, and, as such, would be typically modified by adjectives, we decided to analyse both noun and adjective collocates thereof, because in the Spanish language the syntactic and semantic differences between nouns and adjectives are often "only minor" (Davies, 2006, p. 5). A good example of the latter could be the collocate médico found in the Table 1. This collocate could be identified as both a noun ('physician') and an adjective ('medical' ). In fact, the analysis of the concordances of the collocate médico in our corpus revealed that it was used as a noun on 10 and as an adjective on only 2 occasions.

The analysis of the noun and adjective collocates presented in the Table 1 provides clear "initial indications" (Baker et al., 2013) as to the main themes associated with the noun fisioterapista in the studied texts. Even though médico was the most common collocate of the node term fisioterapista* in the corpus, its next three most frequent collocations were with the terms club, selección and equipo, thus placing the physiotherapy professional in a sports-related company of words.

The most common relevant WordNet domain in which the collocates of the node term fisioterapista* were categorised was the domain of 'Sport' ( 11 collocates), followed by the domain of 'Medicine' ( 5 collocates), while the other relevant domains contained from one to three collocates each (Table 2). Thus, the examination of the categorisation of the collocates of the noun fisioterapista in Ecuadorian newspaper articles revealed its predominant presentation within sports-related rather than health-related contexts.

The analysis of the grammatical gender of the noun fisioterapista showed that this noun was used in masculine approximately six times as often as in feminine, while its use in both grammatical genders in the same article appeared only once in the studied corpus (Table 3).

Table 1: Most Frequent Noun and Adjective Collocates of Noun 'Fisioterapista' in Ecuadorian Newspaper Articles

\begin{tabular}{lccc}
\hline Collocate & Observed frequency & Normalised frequency & $\mathrm{Ml}$ \\
\hline médico & 12 & 174.8 & 5.53 \\
club & 8 & 116.5 & 5.76 \\
selección & 7 & 102.0 & 5.02 \\
equipo & 7 & 102.0 & 4.51 \\
trabajo & 6 & 87.4 & 5.11 \\
rehabilitación & 6 & 87.4 & 5.72 \\
hospital & 6 & 87.4 & 6.75 \\
físico & 6 & 87.4 & 5.40 \\
utilero & 4 & 58.3 & 8.65 \\
recuperación & 4 & 58.3 & 4.86 \\
médicos & 4 & 58.3 & 5.27 \\
años & 4 & 58.3 & 3.41 \\
técnico & 3 & 43.7 & 3.72 \\
Tricolor & 3 & 43.7 & 5.00 \\
Quito & 3 & 43.7 & 3.60 \\
preparador & 3 & 43.7 & 4.88 \\
nutricionista & 3 & 43.7 & 8.97 \\
Nacional & 3 & 43.7 & 4.33 \\
Independiente & 3 & 43.7 & 6.16 \\
entrenador & 3 & 43.7 & 5.16 \\
Ecuador & 3 & 43.7 & 4.55 \\
días & 3 & 43.7 & 4.45 \\
día & 3 & 43.7 & 4.70 \\
diferenciado & 3 & 43.7 & 8.97 \\
cuerpo & 3 & 43.7 & 4.16 \\
\hline n noun or adjective & 0 & & \\
\hline
\end{tabular}

Note. Collocate = noun or adjective collocate; Observed frequency = observed absolute frequency of occurrence of a collocate in the corpus; Normalised frequency $=$ normalised observed frequency of occurrence of a collocate per 1,000,000 words; $\mathrm{MI}=$ mutual information statistic. Statistic cut-off values: $\mathrm{MI} \geq 3.0$ and $\mathrm{LL}>3.84(\mathrm{p}<0.05)$. Minimal collocation frequency $=3$. Function words and personal names were removed. 
Table 2: Most Frequent Noun and Adjective Collocates of Noun 'Fisioterapista' in Ecuadorian Newspaper Articles Categorised According to Most Relevant WordNet Domains

\begin{tabular}{ll}
\hline WordNet domains & Noun and adjective collocates \\
\hline Sport & utilero, preparador, entrenador, club, técnico, Tricolor, selección, equipo, \\
& Nacional, Independiente, diferenciado \\
Medicine, Health & médico, hospital, médicos, nutricionista, rehabilitación \\
Physiology & recuperación \\
Time_Period & años, días, día \\
Administration, Geography & Quito, Ecuador \\
Factotum & trabajo, fisico, cuerpo \\
\hline
\end{tabular}

Table 3: Grammatical Gender of Noun 'Fisioterapista' in Ecuadorian Newspaper Articles

\begin{tabular}{lccc}
\hline Gender & Number of articles & Percent & $95 \% \mathrm{Cl}$ \\
\hline Masculine & 92 & 76.7 & 68.3 to 83.4 \\
Feminine & 15 & 12.5 & 7.6 to 19.7 \\
Masculine and femininea & 1 & 0.8 & 0.0 to 5.0 \\
Undetermined & 12 & 10.0 & 5.7 to 16.8 \\
\hline
\end{tabular}

Note. $95 \% \mathrm{Cl}=95 \%$ Agresti-Coull confidence interval for a percent proportion. aMasculine and feminine: both masculine and feminine grammatical genders of the noun fisioterapista co-occured in the same article.

Although it is quite possible that some of the uses of the noun fisioterapista in masculine were in fact masculine generics used to represent mixed groups in Spanish, its masculine gender looks rather over-represented in the corpus, considering the fact that the actual female to male ratio in the physiotherapy profession in Latin America seems to be about 2:1 or even 3:1, depending on the country, as evidenced by the female to male ratios presented by the member professional organisations of the region, listed on the World Confederation for Physical Therapy web-site (World Confederation for Physical Therapy, 2015). This difficult to explain discordance between the public perception of the physiotherapy professional and the actual workforce situation in relation to gender has been previously referred to as the "unique ambiguity" (Hammond, 2013, p. 10). In any case, even the masculine generics would most certainly lead to overrepresentation of the men in the readers' minds, in comparison to the actually existent pattern (Kaufmann \& Bohner, 2014).

The analysis of the article titles showed that only two of them included the word fisioterapista $(1.7 \% ; 95 \% \mathrm{Cl} 0.1 \%$ to $6.2 \%$ ), one referring to the professional activity of a physiotherapist and another reporting a crime news. No other words related to the physiotherapy profession were found in the article titles.

The newspaper sections in which the article comprising the corpus were published are presented in the Table 4. As can bee seen from the table, more than $70 \%$ of the articles appeared in the sports-related sections of the newspapers.

Table 4: Newspaper Sections where the Articles of the Corpus were Published

\begin{tabular}{lccc}
\hline Newspaper section & Number of articles & Percent & $95 \% \mathrm{Cl}$ \\
\hline DEPORTES & 73 & 60.8 & 51.9 to 69.1 \\
ACTUALIDAD & 12 & 10.0 & 5.7 to 16.8 \\
TENDENCIAS & 11 & 9.2 & 5.0 to 15.8 \\
REGIONALES & 6 & 5.0 & 2.1 to 10.7 \\
Other, sports-related & 12 & 10.0 & 5.7 to 16.8 \\
Other, not sports-related & 5 & 4.2 & 1.5 to 9.6 \\
Not indicated & 1 & 0.8 & 0.0 to 5.0 \\
\hline
\end{tabular}

Note. $95 \% \mathrm{Cl}=95 \%$ Agresti-Coull confidence interval for a percent proportion.

The content analysis of the tags assigned by the publishers to the online versions of the articles forming the corpus revealed that $58.7 \%$ of the online tag tokens were sports-related and $13.0 \%$ health related, among which less than $2 \%$ had anything to do with physiotherapy or physiotherapists (Table 5). 
Table 5: Most Common Tags Assigned to the Articles of the Corpus

\begin{tabular}{llccc}
\hline Tag category & Tag examples & Frequency & Percent & $95 \% \mathrm{Cl}$ \\
\hline Sports-related & fútbol, Selección de Ecuador, fútbol ecuatoriano, Liga de Quito, deportes & 176 & 58.7 & 53.0 to 64.0 \\
Health-related & salud, cirugpias, medicina, atención médica, consultorio médico, crioterapia & 39 & 13.0 & 9.6 to 17.3 \\
Other & Ecuador, sintesis noticiosa, Colombia, crimen, EE.UU., accidentes, Alemania & 85 & 28.3 & 23.5 to 33.7 \\
\hline
\end{tabular}

Note. $95 \% \mathrm{Cl}=95 \%$ Agresti-Coull confidence interval for a percent proportion.

The distorted image of a health profession in the media of communication found in this study was in agreement with earlier observations in the field of physiotherapy (Hammond, 2013, pp. 9-11) and related health care occupations (Barizon Luchesi, Paul, \& Costa Mendes, 2013; Summers \& Summers, 2015, pp. 37-54).

Our study was primarily based on the corpus analysis tool kit provided by the AntConc software (Anthony, 2013). Recently, several text analytic tools has been developed providing convenient ways to simplify and reduce textual data dimensionality with the use of collocation networks (Brezina et al., 2015), cluster analysis, and multidimensional scaling (Cleophas \& Zwinderman, 2015, pp. 3-46). These methods permit revealing hidden lexical patterns and performing easy visual analysis of the results, which may be useful in analysing the image of physiotherapy practitioners in both printed and social media (Voznesenskyy, Zaviryukha, Figueroa-Andrade, \& Moya-Collantes, 2015).

\section{Conclusion}

The outcomes of our research indicate that the corpus-driven analysis is a feasible tool to sketch the image of the Ecuadorian physiotherapy practitioner in the online versions of national printed media of communication.

In general, the newspaper articles studied presented to the public a stereotyped and largely distorted image of the physiotherapist as a predominantly male practitioner acting in the sports-related context, and generally ignored the diverse areas of practice of the profession and its actual focus on the multidisciplinary work within the health care field.

A full-scope research including other Ecuadorian national, regional, and local printed media with the content available online is justified on the basis of the findings of the present study.

\section{References}

Anthony, L. (2013). Developing AntConc for a new generation of corpus linguists. In A. Hardie \& R. Love (Eds.). Abstract Book of the Corpus Linguistics Conference CL 2013 (pp. 14-16). Lancaster, United Kingdom: University Centre for Computer Corpus Research on Language. Retrieved from http://ucrel.lancs.ac.uk/cl2013/

Baker, P., Gabrielatos, C., Khosravinik, M., Krzyżanowski, M., McEnery, T. \& Wodak, R. (2011). ¿Una sinergia metodológica útil? Combinar análisis crítico del discurso y lingüística de corpus para examinar los discursos de los refugiados y solicitantes de asilo en la prensa británica. Discurso y Sociedad, 5(2), 376-416. Retrieved from http://www.dissoc.org/

Baker, P., Gabrielatos, C., \& McEnery, T. (2013). Sketching Muslims: A corpus driven analysis of representations around the word 'Muslim' in the British press 1998-2009. Applied Linguistics, 34(3), 255-278. doi: 10.1093/applin/ams048

Baker, P. \& Levon, E. (2015). Picking the right cherries?: A comparison of corpus-based and qualitative analyses of news articles about masculinity. Discourse \& Communication, 9(2), 1-16. doi:10.1177/1750481314568542

Baker, P. \& McEnery, T. (2014) 'Find the doctors of death': press representation of foreign doctors working in the NHS, a corpus based approach. In A. Jaworski \& N. Coupland (Eds.), The discourse reader (3rd ed.). London: Routledge.

Barizon Luchesi, L., Paul, P., \& Costa Mendes, I. A. (2013). Image of nursing in research papers: A literature review. Journal of Nursing UFPE, 7(spe), 5686-5694. doi:10.5205/reuol.4773-39313-1-SM.0709esp201307

Barrs, K. (2015). Review: Corpus Linguistics: Method, Analysis and Interpretation (massive open online course). Corpora, 10(1), 127130. doi: $10.3366 /$ cor. 2015.0069

Bentivogli, L., Forner, P., Magnini, B., \& Pianta, E. (2004). Revising WordNet domains hierarchy: Semantics, coverage, and balancing. In G. Sérasset, S. Armstrong, C. Boitet, A. Popescu-Belis, \& D. Tufis (Eds.), Proceedings of COLING 2004 Post Conference Workshop on Multilingual Linguistic Resources (pp. 101-108). Geneva, Switzerland: University of Geneva.

Bilder, C. R., Zhang, B., Schaarschmidt, F., \& Tebbs, J. M. (2010). binGroup: A package for group testing. The $R$ Journal, 2(2), 56-60. Retrieved from https://journal.r-project.org/

Brezina, V., McEnery, T. \& Wattam, S. (2015). Collocations in context: A new perspective on collocation networks. International Journal of Corpus Linguistics, 20(2), 139-173. doi 10.1075/ijcl.20.2.01bre

Cendejas, E., Barceló, G., Sidorov, G., Gelbukh, A., \& Chanona-Hernandez, L. (2012). Redes de palabras alineadas como recurso en la extracción de equivalencias léxicas de traducción y su aplicación en la alineación. Polibits, 46, pp. 39-47. Retrieved from http://www.scielo.org.mx/scielo.php

Cleophas, T. J. \& Zwinderman, A. H. (2015). Machine learning in medicine - a complete overview [Springer eBooks version]. 
doi:10.1007/978-3-319-15195-3

Corporación Humanas Ecuador. (2011). Las mujeres en los medios: Análisis cualitativo del Observatorio Medios y Violencia de Género contra las Mujeres de Ecuador. Quito, Ecuador: Corporación Humanas Ecuador. Retrieved from http://www.humanas.org.ecl

Crawford, P., Brown, B., Baker, C., Tischler, V., \& Abrams B. (2015). Health humanities. New York, NY: Palgrave Macmillan.

Davies, M. (2006). A frequency dictionary of Spanish: Core vocabulary for learners. New York, NY: Routledge.

Enguix Oliver, S. \& Gallardo Paúls, B. (2014). El encuadre de los temas de salud: Cobertura en prensa escrita del daño cerebral adquirido. Ámbitos, (26). Retrieved from http://ambitoscomunicacion.com/

Gabrielatos, C., McEnery, T., Diggle P. J., \& Baker, P. (2012). The peaks and troughs of corpus-based contextual analysis. International Journal of Corpus Linguistics, 17(2), 151-175. doi:10.1075/ijcl.17.2.01gab

Hammond, J. A. (2013). Doing gender in physiotherapy education: A critical pedagogic approach to understanding how students construct gender identities in an undergraduate physiotherapy programme in the United Kingdom (Doctoral thesis, Kingston University, London, United Kingdom). Retrieved from http://eprints.kingston.ac.uk/

Kaufmann, C. \& Bohner, G. (2014). Masculine generics and gender-aware alternatives in Spanish. IFFOnZeit - Online Journal of the Interdisciplinary Center for Research on Women and Gender at the University of Bielefeld, 4(3), 8-17. Retrieved from http://www.iffonzeit.de/

R Core Team. (2015). R: A language and environment for statistical computing. Vienna, Austria: R Foundation for Statistical Computing. Retrieved from http://www.R-project.org/

Rezaei-Adaryani, M., Salsali, M., \& Mohammadi, E. (2012). Nursing image: an evolutionary concept analysis. Contemporary Nurse, 43(1), 81-89. doi:10.5172/conu.2012.43.1.81

Stvan, L. S. (2013). Stress management: corpus-based insights into vernacular interpretations of stress. Communication \& Medicine, 10(1), 81-93. doi: 10.1558/cam.v10i1.81

Summers, S. \& Summers, H. (2015). Saving lives: Why the media's portrayal of nursing puts us all at risk (2nd ed.). New York, NY: Oxford University Press.

Voznesenskyy, S., Zaviryukha, T., Figueroa-Andrade, P., \& Moya-Collantes, S. (2015, October). Análisis de conglomerados jerárquico y escalamiento multidimensional en la exploración de la imagen del fisioterapista ecuatoriano en la prensa escrita: Estudio de factibilidad. Paper presented at the First International Congress "Docencia, Investigación en Salud y Vinculación con la Colectividad", Quito, Ecuador.

World Confederation for Physical Therapy. (2015). WCPT Regions. Retrieved from http://www.wcpt.org/regions 